\title{
USING THE SPH METHOD FOR MODELING THE CRYSTALLIZATION PROCESS OF ALUMINUM ALLOYS
}

\author{
${ }^{1}$ Professor Tatiana Lysenko, ${ }^{2}$ Associate Professor Yuriy Morozov, \\ ${ }^{3}$ Kyryll Kreitser, ${ }^{4}$ Evgeny Kozishkurt, \\ Ukraine, Odessa, Odessa National Polytechnic University, \\ ${ }^{1}$ Head of Department of Foundry Process Technologies and Management, \\ ${ }^{2}$ Department of Higher Mathematics and Systems Modeling, \\ ${ }^{3}$ Head of the research laboratory of special casting methods, \\ ${ }^{4}$ Graduate student of Department of Foundry Process Technologies and Management
}

DOI: https://doi.org/10.31435/rsglobal_ws/31032020/6981

\begin{abstract}
ARTICLE INFO
Received: 17 January 2020

Accepted: 13 March 2020

Published: 31 March 2020

\section{KEYWORDS}

Crystallization,

SPH

method,

aluminum alloys,

low-pressure casting.

ABSTRACT

The purpose of the study was to obtain castings with increased mechanical properties by low-pressure casting using excess pressure on the crystallized casting. The simulation of the process of filling and crystallization of prototypes using the SPH method was carried out. The studies were carried out on a modernized low-pressure injection molding machine model U8261. Prototypes were obtained from AK7ch alloy, special attention is paid to interfacial interaction and intensification of the heat transfer process due to the application of excess pressure. Based on the data obtained, it was found that during crystallization under excessive pressure there is a supercooling effect that reduces the casting solidification time. The use of the SPH method for modeling foundry processes has shown a high level of reliability and requires further development.
\end{abstract}

Citation: Tatiana Lysenko, Yuriy Morozov, Kyryll Kreitser, Evgeny Kozishkurt. (2020) Using the SPH Method for Modeling the Crystallization Process of Aluminum Alloys. World Science. 3(55), Vol.1. doi: 10.31435/rsglobal_ws/31032020/6981

Copyright: (C) 2020 Tatiana Lysenko, Yuriy Morozov, Kyryll Kreitser, Evgeny Kozishkurt. This is an open-access article distributed under the terms of the Creative Commons Attribution License (CC BY). The use, distribution or reproduction in other forums is permitted, provided the original author(s) or licensor are credited and that the original publication in this journal is cited, in accordance with accepted academic practice. No use, distribution or reproduction is permitted which does not comply with these terms.

Introduction. The modern foundry aims to produce high-quality competitive castings with a minimum manufacturing cost. One way to solve this problem is to apply pressure, which plays a key role in many special types of castings. The combination of advantages and disadvantages of the lowpressure casting method is one of the most effective. When casting by this method, it is possible to exert subsequent pressure on the crystallized casting [1,2].

Recent studies show that it is possible to regulate the properties of the finished casting already at the initial stages of mold filling and crystallization. This allows you to significantly improve the mechanical properties of the casting [3,4].

In the transition to new production technologies to avoid significant investment, it is necessary to apply computer simulation at the design stage of the technological process. This solution allows you to observe the processes that occur in the casting and to understand why there is a defect in this casting with given specific technological parameters. Then there is the opportunity to offer effective technological solutions that can be checked again using simulation [5].

The meshless method of smooth particles (SPH) is perfectly suitable for modeling casting processes [6,7]. For its implementation, information on the connections between nodes is not required, which avoids the difficulties associated with the construction of the mesh, as well as the need to track inter-node communications at each time step [8]. 
The SPH method allows one to more reliably simulate the processes of filling [9] and crystallization [10], as well as considering latent heat released during melting and absorbed during solidification.

Purpose of the research: the study of the influence of excess pressure on the crystallizing casting of Ak7ch alloy during low-pressure casting. Simulation of filling a mold with an alloy followed by crystallization under pressure using the SPH method.

Material and methods. The studies were carried out on prototypes in the form of plates made of AK7ch alloy obtained on a modernized low-pressure casting machine model U8261. After filling the chill cavity with the melt, an excess pressure of 200-900 KPa was applied to the crystallizing sample (Fig. 1). The chemical composition and dimensions of the test samples are presented in tables 1 and 2, respectively.

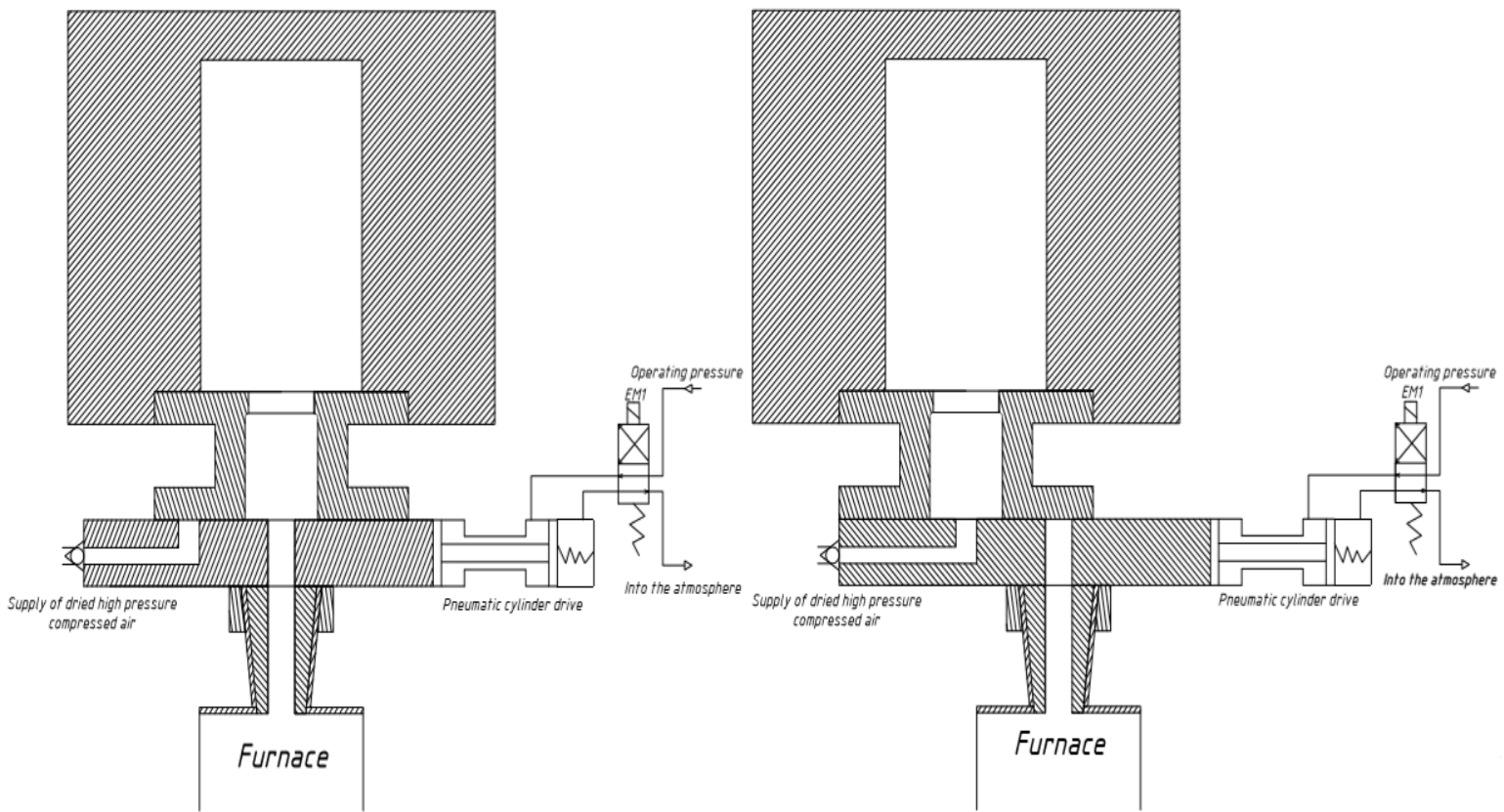

Fig. 1. Scheme for obtaining prototypes

Table 1. Chemical composition in \% of AK7ch alloy

\begin{tabular}{|c|c|c|c|c|c|c|c|c|c|c|c|}
\hline $\mathrm{Fe}$ & $\mathrm{Si}$ & $\mathrm{Mn}$ & $\mathrm{Al}$ & $\mathrm{Cu}$ & $\mathrm{Pb}$ & $\mathrm{Be}$ & $\mathrm{Mg}$ & $\mathrm{Zn}$ & $\mathrm{Sn}$ & Impurities & - \\
\hline up & $6-$ & up & $89.6-$ & up & up & up & $0.2-$ & up & up & total 2 & $\begin{array}{c}\mathrm{Ti}+\mathrm{Zr}< \\
\text { to }\end{array} 1.5$ \\
8 & to 0.5 & 93.8 & to 0.2 & to 0.05 & to 0.1 & 0.4 & to 0.3 & to 0.01 & & \\
\hline
\end{tabular}

Table 2. Dimensions of the prototypes

\begin{tabular}{|c|c|c|c|}
\hline № of the prototype & $S$, mm (thickness) & B, mm (width) & H, mm (height) \\
\hline 1 & 15 & 100 & 250 \\
\hline 2 & 20 & 100 & 250 \\
\hline 3 & 45 & 100 & 250 \\
\hline 4 & 60 & 100 & 250 \\
\hline
\end{tabular}

For numerical modeling of crystallization processes, it makes sense to use the particle method (SPH - "Smooth Particle Hydrodynamics"), since the use of other approaches is associated with significant technical or theoretical difficulties. The method can be implemented in a conservative form, and its feature is a simple transition to the three-dimensional case.

The essence of this method is to approximate the formula $[11,12,13,14]$

$$
a(x)=\int_{R} a(x) \delta\left(x-x_{i}\right) d x
$$


with the following chain of transformations. At the beginning we replace the generalized function $\delta(x)$ with an analytic function $W\left(x-x_{i}, h\right)$, which is called the smoothing kernel, and $h-$ smoothing radius. As a result, we get

$$
\bar{a}(x)=\int_{R} a(x) W\left(x-x_{i}, h\right) d x
$$

The kernel $W\left(x-x_{i}, h\right)$ must satisfy the conditions

$$
\int_{R} W(x, h) d x=1 \text { и } W(x, h) \underset{h \rightarrow 0}{\longrightarrow} \delta(x) \text {. }
$$

In the works of Monaghan [11,12,13] it was proved that subject to these conditions, the approximation provides the order $O\left(h^{2}\right)$. particles:

The following transformation consists of replacing integration by summing over neighboring

$$
\bar{a}(x)=\sum_{j} \frac{m_{j} a_{j}}{\rho_{j}} W\left(x-x_{j}, h\right)
$$

Using this approximation significantly simplifies the calculation of the gradient of the field function since it is enough to analytically differentiate the smoothing kernel, which will give

$$
\frac{\partial \bar{a}(x)}{\partial x^{\alpha}}=\sum_{j} \frac{m_{j} a_{j}}{\rho_{j}} \frac{\partial W\left(x-x_{j}, h\right)}{\partial x^{\alpha}}
$$

The equations of fluid motion in terms of SPH are written as follows.

Continuity equation

$$
\frac{\partial \rho_{i}}{\partial t}=\rho_{i} \sum_{j=1}^{N} \frac{m_{j}}{\rho_{j}}\left(v_{i}^{\beta}-v_{j}^{\beta}\right) \frac{\partial W_{i j}}{\partial x_{i}^{\beta}}
$$

Momentum equations

$$
m_{i} \frac{\partial v_{i}^{\alpha}}{\partial t}=\sum_{j=1}^{N} m_{i} m_{j}\left(\frac{\sigma_{i}^{\alpha \beta}}{\rho_{i}^{2}}+\frac{\sigma_{j}^{\alpha \beta}}{\rho_{j}^{2}}+\Pi_{i j}\right) \frac{\partial W_{i j}}{\partial x_{i}^{\beta}}
$$

where $i$-the particle in question; $N$ - the number of neighboring particles; $m$-weight; $W_{i j}=W\left(x_{i}-x_{j}, h\right)$-interpolation kernel; As the interpolation kernel, choose

$$
W\left(x_{i}-x_{j}, h\right)=\alpha_{d}\left\{\begin{array}{cc}
\frac{2}{3}-\frac{9}{8} r_{i j}^{2}+\frac{19}{24} r_{i j}^{3}-\frac{5}{32} r_{i j}^{4} & 0 \leq r_{i j} \leq 2 \\
0 & r_{i j}>2
\end{array}, \quad r_{i j}=x_{i}-x_{j}\right.
$$

Where $\alpha_{d}$ takes the values $\frac{1}{h}, \frac{15}{7 \pi h^{2}}$ and $\frac{315}{208 \pi h^{3}}$ for one, two, and three-dimensional space, respectively.

$h$-smoothing length; $v_{i}^{\alpha}=\frac{d x_{i}^{\alpha}}{d t} ; \rho_{i}=\sum_{i=1}^{N} m_{j} W_{i j}-$ density of the $i-$ particle; $\Pi_{i j}-$ artificial viscosity [11]:

Here

$$
\Pi_{i j}=\left\{\begin{array}{cc}
\frac{-\alpha \bar{c}_{i j} \mu_{i j}+\beta \mu_{i j}^{2}}{\bar{\rho}_{i j}} & \text { if }\left(v_{i}-v_{j}\right)\left(x_{i}-x_{j}\right)<0 \\
0 & \text { otherwise }
\end{array}\right.
$$

$$
\mu_{i j}=\frac{h_{i j}\left(v_{i}-v_{j}\right)\left(x_{i}-x_{j}\right)}{\left(x_{i}-x_{j}\right)^{2}+0.01 h_{i j}^{2}}, \quad \bar{c}_{i j}=\frac{c_{i}+c_{j}}{2}, \quad \bar{\rho}_{i j}=\frac{\rho_{i}+\rho_{j}}{2}, \quad h_{i j}=\frac{1}{2}\left(h_{i}+h_{j}\right)
$$

where $c_{i}$ and $c_{j}$ - the speed of sound at points $i$ and $j$, respectively; $a$ and $b$ - artificial viscosity coefficients. 
The introduction of artificial viscosity not only provides the necessary dispersion but also prevents non-physical penetration for particles approaching each other.

The equation of state [11], which gives the relationship between the particle density and fluid pressure, has the form:

$$
P=P_{0}\left[\left(\frac{\rho}{\rho_{0}}\right)^{\gamma}-1\right]
$$

where $P_{0}-$ pressure value; $\rho_{0}-$ reference density; $\gamma=7$ for liquids or liquid metals; $\frac{\gamma P_{0}}{\rho_{0}}=100 V^{2}=c_{s}^{2}, V-$ maximum fluid velocity.

In the SPH method, heat increment due to thermal conductivity is calculated as follows [12].

$$
Q_{h c, i}=-\sum_{j=1}^{N} \frac{4 m_{j}}{\rho_{j}} \frac{k_{i} k_{j}}{k_{i}+k_{j}}\left(T_{i}-T_{j}\right) \frac{\partial W_{i j}\left(\left|x_{i}-x_{j}\right|, h\right)}{\partial x_{i}}
$$

where $Q_{h c, i}$-an increase in heat per unit volume of the $i$ - particle due to thermal conductivity, $k_{i}, k_{j}$-the heat conductivity coefficients for the $i$-and $j$-particle, respectively. $T_{i}, T_{j}-$ temperature of he $i$ - and $j$-particle.

The heat transfer between the crystallizer and the molten metal can be calculated as follows

$$
Q_{h t, i}=-2 h^{2} \pi \frac{\rho_{i}}{m_{i}} \sum_{j=1}^{N} \omega_{i k}\left(\frac{m_{i}}{\rho_{i}}+\frac{m_{k}}{\rho_{k}}\right)\left(T_{i}-T_{k}\right) W_{i j}\left(\left|x_{i}-x_{k}\right|, h\right)
$$

The equation of the heat transfer process looks like this

$$
\rho_{i} \frac{d u_{i}}{d t}=Q_{h t, i}+Q_{h t, i}
$$

where $u_{i}$-internal energy per unit volume of the $i-$ particle.

Crystallization and shrinkage can be expressed as changes depending on temperature, viscosity and density, respectively.

The simulation of the moving boundary of the contact of several phases in SPH is based on particle interactions (Fig. 2).

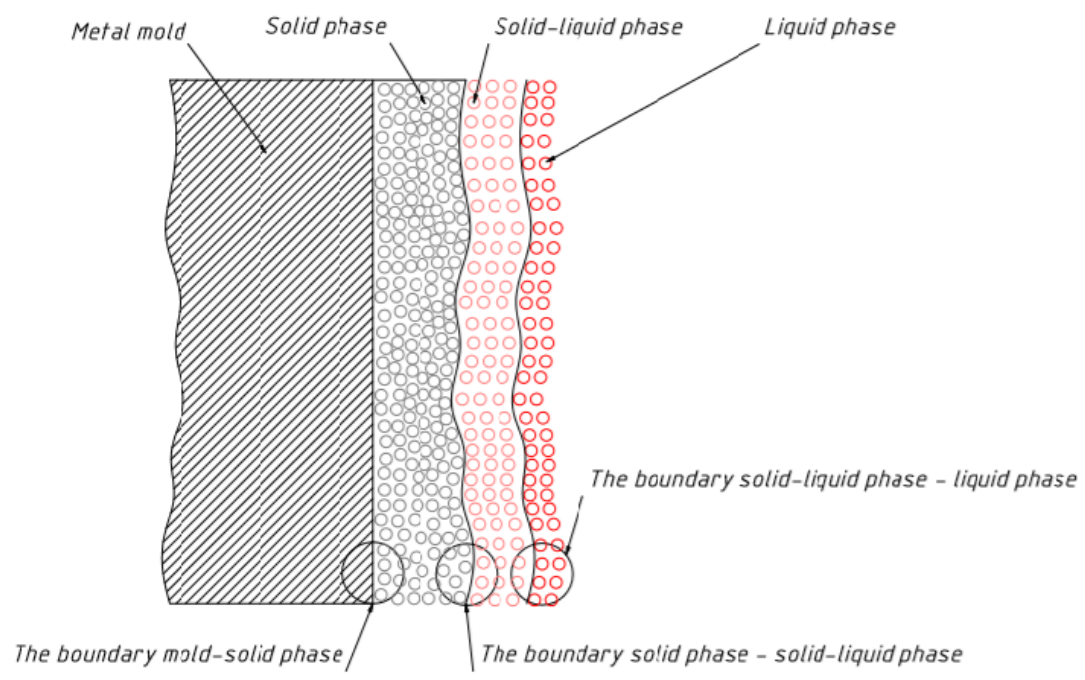

Fig. 2. Moving interface between phases during the crystallization of aluminum alloy

To avoid this non-physical behavior, an interaction force like the Lennard-Jones repulsive force is introduced, which is applied to particles from various materials at the interface when they come together. This force is applied in pairs to particles along their common axis as follows [12]. 


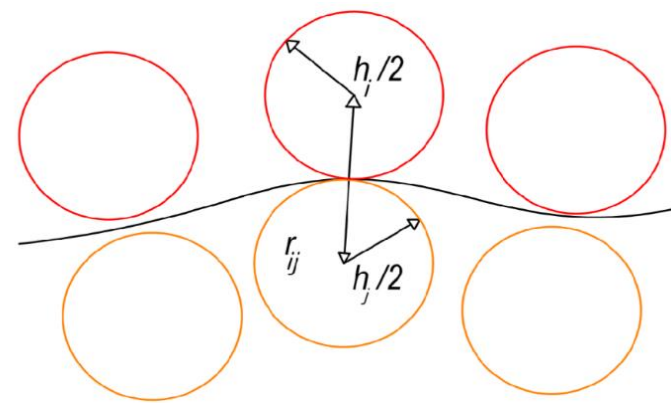

Fig. 3. Particle interaction at the phase boundary

$$
f_{i j}(r)=\left\{\begin{array}{cc}
D\left[\left(\frac{h_{0}}{r_{i j}}\right)^{4}-\left(\frac{h_{0}}{r_{i j}}\right)^{2}\right]\left(x_{i j} / r_{i j}^{2}\right) & r_{i j}<r_{0} \\
0 & r_{i j}>r_{0}
\end{array}\right.
$$

where $i$ and $j$ numbers of particles belonging to different phases; $D$ - parameter depending on the square of the maximum speed; $r_{i j}$-distance between two particles;

or

$$
f_{i j}(r)=\left\{\begin{array}{cc}
\bar{D}\left[\left(\frac{h_{i j}}{r_{i j}}\right)^{n_{1}}-\left(\frac{h_{i j}}{r_{i j}}\right)^{n_{2}}\right]\left(x_{i j} / r_{i j}^{2}\right) & h_{i j} / r_{i j} \geq 1 \\
0 & h_{i j} / r_{i j}<1
\end{array}\right.
$$

where $\bar{D}, n_{1}, n_{2}$ - the parameters that are selected depending on the problem being solved.

Research results. The simulation was carried out in the ANSYS program, which was used to fill the cast-iron chill with Ak7ch alloy using the meshless SPH method (Fig. 4).
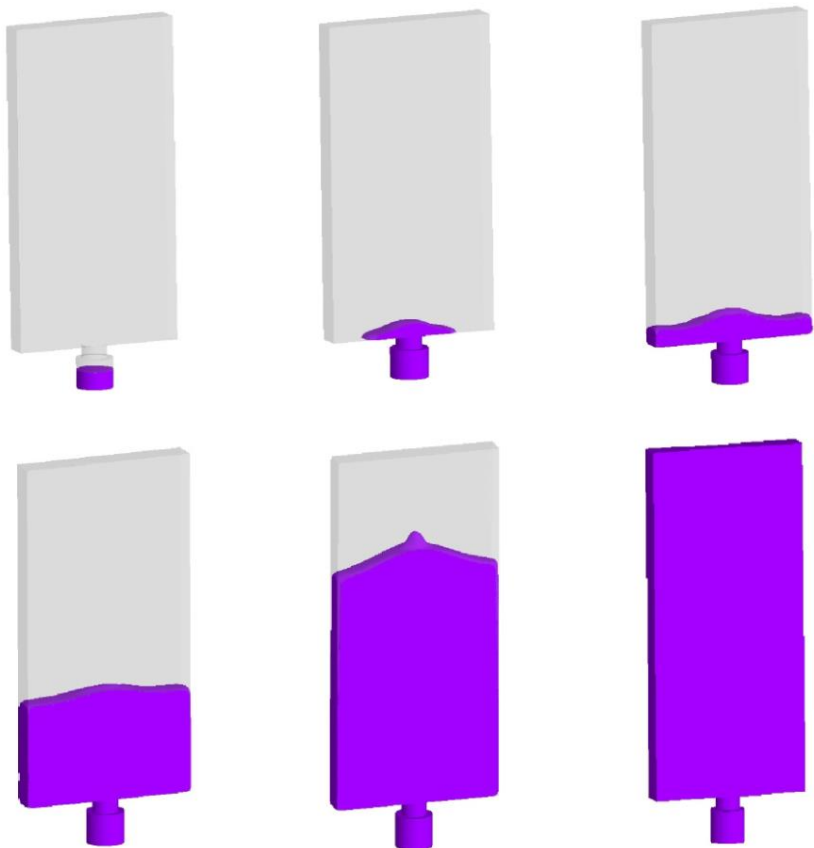

Fig. 4. Modeling the process of filling the chill cavity

Modeling of the processes of filling and crystallization was carried out on prototype No. 1. The experimental prototype filling time was $17.2 \mathrm{~s}$, and the calculated time was $16.4 \mathrm{~s}$. The error is $4.65 \%$, which allows us to consider the results obtained accurately. The calculated filling time was obtained during the simulation. 
Then, the solidification process was simulated with external pressure applied to the crystallizing sample and without external pressure applied (Fig. 5.6).
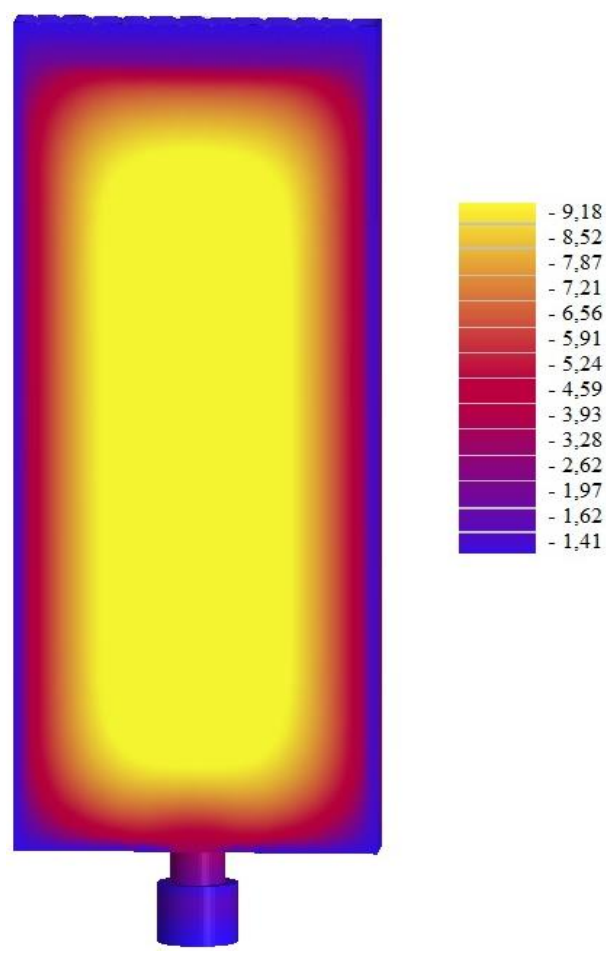

Fig. 5. The time of solidification of the layers of the prototype without applying external pressure, s.

The total solidification time of the prototype without external pressure during crystallization was $9.18 \mathrm{~s}$, while with the application of an overpressure of $900 \mathrm{KPa}$ it was $7.78 \mathrm{~s}$, which is explained by the presence of supercooling (Fig. 6).

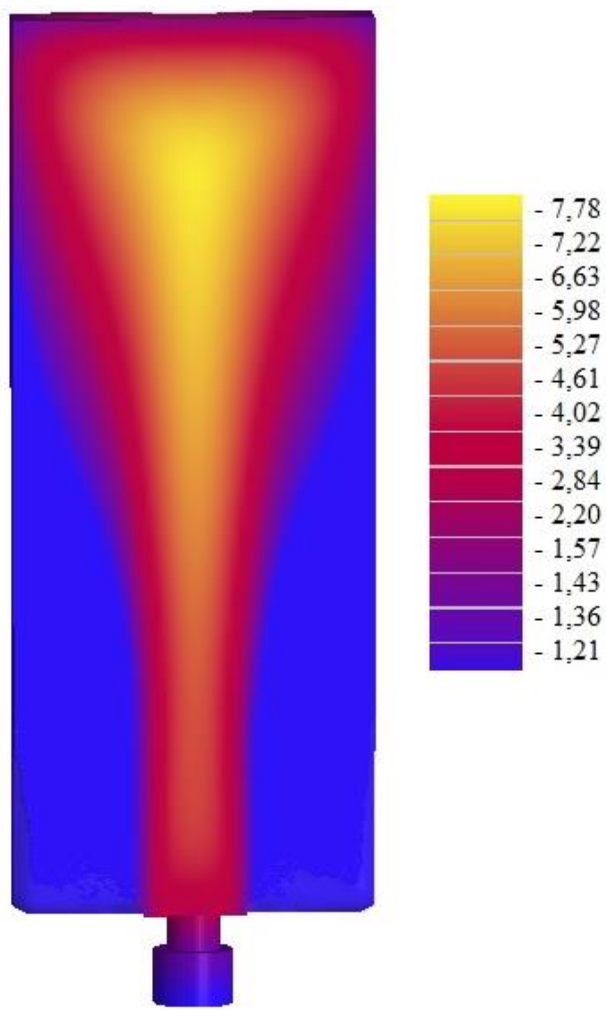

Fig. 6. The time of layer-by-layer solidification of the prototype with the application of external pressure, $s$. 
The prototypes obtained using the technology described above were tested for strength (Fig. 8) and Brinell hardness (Fig. 7).

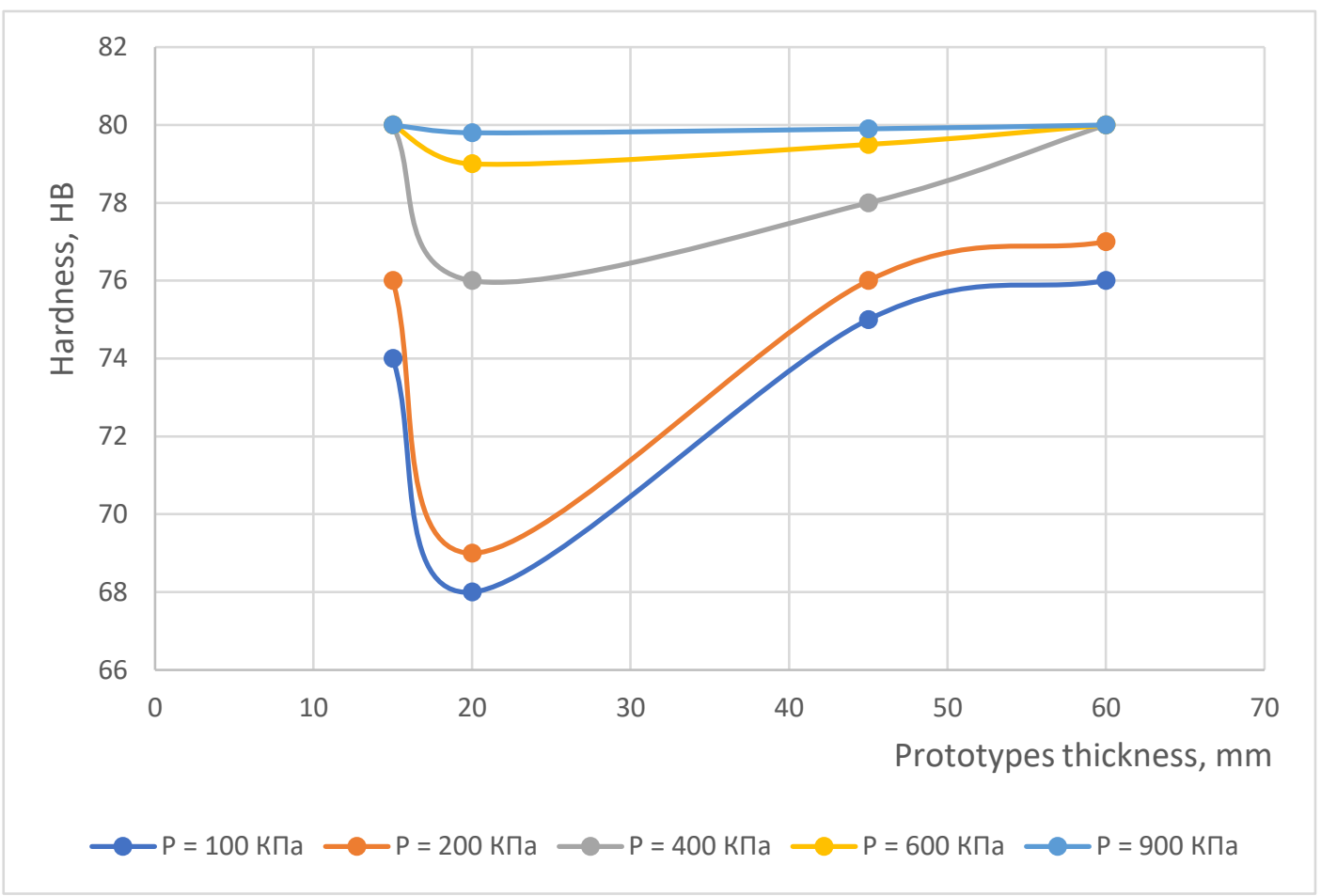

Fig. 7. Change in AK7ch alloy hardness by thickness of casting from pressure during crystallization

Tests have shown that overpressure from 200 to $600 \mathrm{kPa}$ slightly increases the hardness index, while from 600 to $900 \mathrm{kPa}$ there is a noticeable increase in tensile strength by $30 \%$ (DSTU requirements $\geq 60$ ). When applying the pressure of $900 \mathrm{KPa}$, the tensile strength is equalized over the entire thickness of the casting.

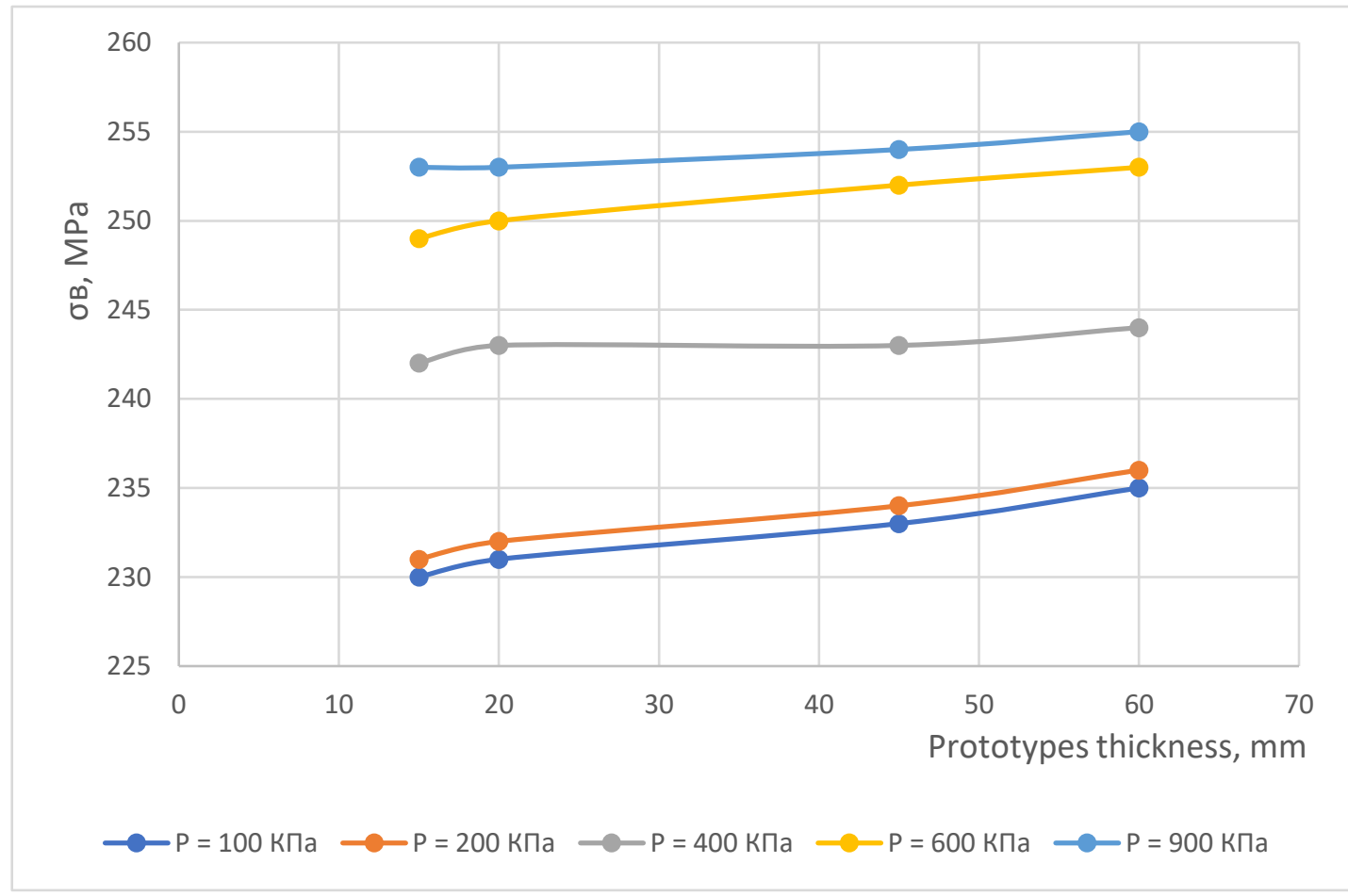

Fig. 8 Changing the tensile strength of the AK7h alloy in the thickness of the prototype from the value of pressure during crystallization 
A similar picture can be observed when measuring the tensile strength of samples with a pressure value during crystallization of $600-900 \mathrm{kPa}$. The indicated mechanical property is increased by $23 \%$ (DSTU requirements $\geq 206$ ).

\section{Conclusions.}

1. Simulation of the filling process using the SPH method has shown a high level of adequacy and is applicable in foundry production.

2. Crystallization under excessive pressure reduces the solidification time of aluminum alloys because of supercooling.

3. The use of excessive pressure during the crystallization of aluminum castings from the Ak7ch alloy increases the mechanical properties by $20-30 \%$.

4. Increasing the overpressure from 600 to $900 \mathrm{KPa}$ significantly equalizes the distribution of mechanical properties throughout the casting volume.

\section{REFERENCES}

1. Борисов Г.П. Повышение качества отливок из алюминиевых сплавов. Оборудование и инструмент для профессионалов. 2006. 1(73): 21-28.

2. Безпалько В.И. Литье с кристаллизацией под давлением тонкостенных отливок из силуминов. Литейное производство. 2013. 6: 21-22.

3. Фасевич Ю.Н., Рудницкий Ф.И. Разработка методики экспериментальных исследований управления кристаллизацией литых заготовок путем оптимизации теплофизических свойств элементов литниковой системы. Литье и металлургия. 2018. 3:36-42.

4. Чуркин Б.С., Чуркин А.Б., Гофман Э.Б., Категоренко Ю.И. Оптимальное управление заливкой форм при литье под регулируемым давлением. Литье и металлургия. 2002. 2: 71-75.

5. Khan M.A., Sheikh A.K. A comparative study of simulation software for modelling metalcasting processes. International Journal of Simulation Modelling. 2018. 17(2): 197-209.

6. Monaghan J. J. Simulating free surface flows with SPH. Journal of Computational Physics. 1994. 110(2): 399-406.

7. Monaghan J. J. Smoothed particle hydrodynamics. Reports on Progress in Physics. 2005. 68: 1703-1759.

8. Paul W. Cleary Extension of SPH to predict feeding, freezing and defect creation in low pressure die casting. Applied Mathematical Modelling. 2010. 34: 3189-3201.

9. Wen-jiong Cao, Zhao-yao Zhou, Fang-ming Jiang Smoothed particle hydrodynamics modeling and simulation of foundry filling process. Transactions of Nonferrous Metals Society of China. 2015. 25: 2321-2330.

10. Amirsaman Farrokhpanah, Markus Bussmann, Javad Mostaghimi New smoothed particle hydrodynamics (SPH) formulation for modeling heat conduction with solidification and melting. Numerical Heat Transfer, Part B: Fundamentals. 2017. 71(4): 299-312.

11. Monaghan JJ (1992) Smoothed particle hydrodynamics. Annu Rev Astron Astrophys 30:543-574.

12. Monaghan JJ (1994) Simulating free surface flows with SPH. J Comput Phys 110:399-406.

13. Monaghan JJ (2005) Smoothed particle hydrodynamics. Rep Prog Phys 68(8):1703-1759.

14. Cleary PW, Prakash M, Ha J, Stokes N, Scott C (2007) Smooth particle hydrodynamics: status and future potential. Prog Comput Fluid Dyn 7:70-90. 